\title{
Letters
}

\section{Family history of breast cancer}

\section{Referral guidelines changed after acceptance of 10 minute consultation}

EDITOR-In their 10 minute consultation on family history of breast cancer Lucassen and Watson drew attention to the recently published guidelines from the National Institute for Clinical Excellence (NICE) on familial breast cancer. ${ }^{12}$ It is unfortunate that the referral criteria were changed between the acceptance of this article in December 2003 and the final published guidelines in June 2004, which would result in the referral of the patient highlighted in the article for potential mammography screening, rather than for her reassurance.

Women aged 40-49 years at moderate risk of breast cancer are entitled to annual mammograms. ${ }^{2}$ The definition of moderate risk was based on a risk of at least 3\% over the 10 year period from the age of 40 to 50 . Available evidence, particularly from combined analyses of case-control studies of familial risks, ${ }^{3}$ indicates that a woman reaches this category with a first degree relative (mother or sister) with breast cancer when younger than 40 years or two relatives on the same side of the family (one first degree and one second degree or two first degree) diagnosed at any age.

The latter category differs from the draft NICE guidelines and previous referral criteria, which required that the two relatives be diagnosed at an average age of less than $60 .^{4}$ This age restriction was removed because it could not be justified on the basis of the available data. It should be noted, however, that referral on the basis of two elderly close relatives is likely to be restricted to the age groups of 30-49, with referral of only high risk groups (for example, two affected relatives diagnosed at an average age of less than 50 years) outside this age group.

D Gareth Evans consultant geneticist

gareth.evans@CMMC.nhs.uk

Douglas Easton genetic epidemiologist

St Mary's Hospital, Manchester M13 0JH

Competing interests: DGE is chairman of the NICE Guideline Development Group on Familial Breast Cancer, and DE a guideline group member.

1 Lucassen A, Watson E. 10 minute consultation. BMJ 2005;330:26. (1 January.)

McIntosh A, Shaw C, Evans G, Turnbull N, Bahar N, Barclay M, et al. Clinical guidelines and evidence review for the classification and care of women at risk of familial breast cancer. London: National Collaborating Centre for Primary Care, University of Shefleld, 2004. (NICE gideline CG014.)

3 Collaborative Group on Hormonal Factors in Breas Cancer. Familial breast cancer: collaborative reanalysis of individual data from 52 epidemiological studies including 58209 women with breast cancer and 101986 wome without the disease. Lancet 2001;358:1389-99.
4 Cancer Research UK Primary Care Education Research Group. Familial breast and ovarian cancer pack. Oxford: Can-
cer Research UK Primary Care Education Research cer Research UK Primary Care Education Research Group, 2001. www.dphpc.ox.ac.uk/c

\section{Authors' reply}

EDITOR-We thank Evans and Easton for highlighting the inconsistency between our suggested management and that suggested by the NICE guidelines on familial breast cancer. ${ }^{1}$ The purpose of the pedigree in the article was mainly illustrative and used in the context of how to take a family history, which is why we were careful to say "to make sure ... check with guidelines" in the text.

Evans and Easton acknowledge that when we wrote the article the then draft NICE guidelines agreed with our suggestion that the woman in our example would not be offered mammography. Along with many of our clinical colleagues, we were unaware that there had been a change in the final version of the NICE guidelines so that our patient would now be offered mammography. We are not clear why this change was made from a previously fairly widely accepted consensus ${ }^{2}$ since the NICE document does not present supporting evidence for this new recommendation. Although the collaborative paper is cited as evidence, ${ }^{3}$ it only examines the risk from two first degree relatives with breast cancer. This is echoed in the NICE guidance itself: "for women with one first degree and one second degree relative we do not have direct estimates."

There is as yet no evidence that mammography in women under 50 reduces mortality from the disease. Although early detection is possible and there is some consensus that those with a very strong family history of breast cancer should be offered mammography under the age of 50 , much of the evidence on which the NICE guidelines are based is category IV. We suggest that the cut-off point between family history groups for which different managements are suggested is to some extent arbitrary. Mammography in those under 50 is currently through the symptomatic breast screening services, thus putting pressure on already overstretched services. The risk that our patient would develop breast cancer before the age of 50 (when she would enter the national breast screening programme) is approximately $1.5-3 \%$ compared with $1-2 \%$ for the general population.

We commend the NICE committee for their thorough review of an area where evi- dence is currently limited and hope that this correspondence encourages constructive dialogue on implementing the guidelines.

Anneke Lucassen consultant in clinical genetics Wessex Clinical Genetics Service, The Princess Anne Hospital, Southampton SO16 5YA annekel@soton.ac.uk

Eila Watson deputy director

Cancer Research UK Primary Care Education Research Group, University of Oxford, Oxford OX3 7LF

Competing interests: None declared.

1 McIntosh A, Shaw C, Evans G, Turnbull N, Bahar N, Barclay M, et al. Clinical guidelines and evidence review for the classification and care of women at risk of familial breast cancer. London: National Collaborating Centre for Primary Care University of Sheflield, 2004. (NICE guideline CG014.)

2 Cancer Research UK Primary Care Education Research Group. Familial breast and ovarian cancer pack. Oxford: Cancer Research UK Primary Care Education Research Group, 2001. www.dphpc.ox.ac.uk/crcpcerg/resources/ genpack.htm (accessed 5 March 2005)

3 Collaborative Group on Hormonal Factors in Breast Cancer. Familial breast cancer: collaborative reanalysis of individual data from 52 epidemiological studies including 58209 women with breast cancer and 101986 women without the disease. Lancet 2001;358:1389-99.

\section{Authors of TADS study reply to letter raising concerns}

EDITOR-We thank Jureidini et al for their interest in the treatment for adolescents with depression study (TADS) study ${ }^{1}$ but find their critique to lack accuracy, methodological sophistication, scientific rigour, and credibility.

TADS does not consist of "two separate randomised studies." Patients were consecutively randomised to one of the four TADS treatments using a computerised, stratified randomisation algorithm. ${ }^{2}$ Because comparative treatment trials that include both medication and psychotherapy conditions can double blind the conditions treated with medication only, but not those treated with psychotherapy, TADS employed an independent evaluator blind to treatment assignment, while placebo served as a credible, trial wide control. ${ }^{2}$ These are design choices, not design flaws. ${ }^{23}$

Jureidini et al confuse statistical significance with the magnitude of clinical effect. In TADS, combined treatment with fluoxetine and cognitive behaviour therapy proved

\section{bimj.com}

Letters appearing here are an edited selection of rapid responses originally posted on bmj.com

We ask for all letters to the editor to be submitted as rapid responses via bmj.com

For advice see: bmj.com/rapidresponses 
Balance of benefits and risks, for fluoxetine and combined treatment compared with placebo ${ }^{4}$

\begin{tabular}{lccccc} 
Comparison & $\begin{array}{c}\text { Absolute benefit } \\
\text { increase (\%) }\end{array}$ & $\begin{array}{c}\text { No needed to } \\
\text { treat (NNT) }\end{array}$ & $\begin{array}{c}\text { Absolute risk } \\
\text { increase (\%) }\end{array}$ & $\begin{array}{c}\text { No needed to } \\
\text { harm (NNH) }\end{array}$ & NNT:NNH \\
\hline Fluoxetine $v$ placebo & 27 & 4 & 4.7 & 5.3 & 5.3 \\
\hline Combined treatment $v$ placebo $^{*}$ & 37 & 3 & 2 & 50 & 16.7 \\
\hline
\end{tabular}

${ }^{*}$ Combined treatment includes fluoxetine and cognitive behaviour therapy.

superior to placebo and to cognitive behaviour therapy on five of five measures. Fluoxetine alone proved superior to placebo on three of five measures and to cognitive behaviour therapy on five of five measures. Effect sizes and numbers needed to treat, on the primary scalar and categorical dependent measures, indicated that the two fluoxetine conditions showed a moderate to large effect relative to placebo whereas cognitive behaviour therapy did not. The benefits of including fluoxetine (we make no claims about other antidepressants) are therefore readily apparent and clinically meaningful.

With respect to adverse events, Jureidini et al misrepresent the TADS findings. We worked closely with JAMA to document that patients' attrition did not differ by treatment assignment and primarily reflected lack of benefit rather than adverse events; present fully intention to treat analyses of adverse events, which were mild to moderate in severity; point out that adverse events were more common in participants treated with fluoxetine; and highlight data on harm showing a slightly increased risk in patients treated with fluoxetine, which may be minimised by concomitant cognitive behaviour therapy (see table).

People who would deny moderately to severely ill teenagers with major depressive disorder access to fluoxetine (preferably fluoxetine and cognitive behaviour therapy) should ask themselves: "What is the risk of overstating the case for harm due to fluoxetine?"

John S March chief, Child and Adolescent Psychiatry Program for Child Affective and Anxiety Disorders Duke University Child and Family Study Center, 718 Rutherford Street, Room 132, DUMC 3527, Durham, NC 27710, USA jsmarch@acpub.duke.edu

For the TADS Group

1 Jureidini J, Tonkin A, Mansfield PR. TADS study raise concerns. BMJ 2004;329:1343-4. (4 December.)

2 TADS. Treatment for adolescents with depression study (TADS): rationale, design, and methods. J Am Acad Child Adolesc Psychiatry 2003;42(5):531-42.

3 TADS. Fluoxetine, cognitive-behavioral therapy, and their combination for adolescents with depression: treatment for adolescents with depression study (TADS) randomized controlled trial. JAMA 2004;292:807-20.

4 March J. Treatment for adolescents with depression study: stage I ITT outcomes. Food and Drug Administration Psychopharmacologic Drugs Advisory Committee and the Pediatric Advisory Committee, 2004. www.fda.gov/ohrms/ dockets/ac/04/slides/2004-4065S1_04_FDA-March.ppt (accessed $24 \mathrm{Feb} 2005$ ).

\section{Recent advances in non-invasive cardiology}

\section{Article does not mention} echocardiography

EDITOR-The recent review of advances in non-invasive cardiology by Prasad et al does not discuss echocardiography except briefly as an electronic addendum. ${ }^{1}$ A striking omission is three dimensional echocardiography, which has advantages over two dimensional echocardiography in assessing left ventricular volumes and synchrony and for congenital disease and mitral valve disease. ${ }^{2}$ Miniaturisation of machines now allows studies to be conducted anywhere, ${ }^{3}$ so that echocardiography is increasingly being adopted by non-cardiologists. Stress echocardiography has repeatedly been validated for the prediction of coronary stenoses and for stratifying risk and is gaining in use (cardiac workforce requirements in the UK, www.BCS.com). ${ }^{4}$ A fuller account of advances in echocardiography is available.

No competition should occur between different imaging modalities, and the most appropriate option should be used for any particular clinical indication. Echocardiography will always remain essential for the investigation of acutely ill patients since it is portable. Most district hospitals perform 3000-5000 studies each year, and national workforce planning indicates the need for 11-15 echocardiography consultants per million population compared with 2.9 per mil-

lion for nuclear medicine and 1 per million for magnetic resonance (cardiac workforce requirements in the UK, www.BCS.com).

We are concerned that this article could lead health service managers to eschew the relatively inexpensive, effective, safe and widely available echocardiographic techniques for the apparently more alluring, more expensive techniques of magnetic resonance and cardiac computed tomography. All have developing roles either in clinical practice or research, and it is important that they are viewed in proper perspective.

John Chambers president

jboydchambers@aol.com

Kevin Fox president-elect

British Society of Echocardiography, London SW1P 1SB

\section{Alan Fraser president}

European Association of Echocardiography, The

European Heart House, 2035 Route des Colles, Les Templiers-BP 179, 06903 Sophia-Antipolis Cedex, France

Competing interests: None declared.

1. Prasad SK, Assomull RG, Pennell DJ. Recent developments in non-invasive cardiology. BMJ 2004:329:1386-9. ments in non-i

(11 Decembe $)$

Mor-Avi V, Sugeng L, Weinert L, MacEneney P, Caiana EG, Koch R, et al. Fast measurement of left ventricular mass with real-time three-dimensional echocardiography: comparison with magnetic resonance imaging. Circulation 2004;110:1814-8.
3 Roelandt JRTC. Ultrasound stethoscopy: a renaissance of the physical examination? Heart 2003;89:971-4.

the physical examination? Heart 2003;89:971-4. BSE procedure guidelines for the clinical application of stress

The year in echocardiography. J Am Coll Cardiol 2004:43:140-8.

Details of the five other authors are on bmj.com

Coronary angiography using computed tomography has been underplayed

EDITOR-Prasad et al do not discuss the recent developments in cardiac computed tomography. ${ }^{1}$ Coronary angiography using multidetector computed tomography is one of the most impressive advances in non-invasive cardiology for many years. ${ }^{2-4}$ The authors' judgment on the relative merits of the currently available non-invasive cardiac imaging modalities is perhaps questionable.

In Germany and the United States doctors would not agree that magnetic resonance coronary angiography has similar results to computed tomography coronary angiography. The

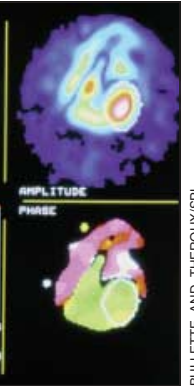
inferior spatial resolution of magnetic resonance imaging, in comparison to multidetector computed tomography, would prevent most authorities on non-invasive coronary artery imaging from making such a statement.

We in the United Kingdom are way behind the rest of the world. Patients in Germany are already undergoing cardiac surgery with the surgeon guided by a computed tomography coronary angiogram. Multidetector computed tomography will have, and in some UK centres undoubtedly already has, a useful clinical role for non-invasive coronary angiography. In our institution coronary angiography using computed tomography can be highly accurate in showing the presence or absence of significant coronary artery disease.

In six months 64 row multidetector cardiac computed tomography capable of imaging the whole heart in less than 10 seconds and offering submillimetre isotropic resolution will be available in the United Kingdom. The sooner UK cardiologists and radiologists become aware of this technology and learn how best to use it, the better. It is new, it is different, and it should be embraced.

G Morgan-Hughes cardiology specialist registrar Gareth.Morgan-Hughes@phnt.swest.nhs.uk

C A Roobottom consultant radiologist

N Manghat radiology specialist registrar

A J Marshall consultant cardiologist

Derriford Hospital, Plymouth PL6 8DH

Competing interests: None declared.

1 Prasad SK, Assomull RG, Pennell DJ. Recent developments in non-invasive cardiology. BMJ 2004;329:1386-9. (11 December.) 
2 Nieman K, Cademartiri F, Lemos P, Raaijmakers R, Pattynama P, de Feyter P. Reliable non-invasive coronary angiography with fast submillimetre multislice spiral comangiography with fast submillimetre multislice spir

3 puted tomography. Circulation 2002;106:2051-4. Ropers D, Baum U, Pohle K et al. Detection of coronary
artery stenosis with thin-slice multi-detector row spiral artery stenosis with thin-slice multi-detector row spiral
computed tomography and multiplanar reconstruction.

Circulation 2003;107:664-6.
4 Kuettner A, Trabold T, Schroeder S et al. Noninvasive detection of coronary lesions using 16-detector multislice spiral computed tomography technology: initial clinical results. J Am Coll Cardiol 2004;44:1230-7.

5 Morgan-Hughes G, Roobottom C, Owens P, Marshall A Highly accurate coronary angiography with submillimetre 16 slice computed tomography Heart (in press).

\section{Authors' reply}

EDITOR-There have been some tremendous recent advances across the spectrum of imaging modalities in cardiology, and to do justice to all of them in a limited review article is difficult. In addition, the aim of this article, as defined at the outset by the $B M J$, was readability for the non-specialist reader.

Not surprisingly, we agree with Chambers et al that two exciting areas in echocardiography are the tissue Doppler assessment of myocardial contractility and stress contrast echocardiography. These have had less current clinical impact, however, certainly at the time of writing of our article. The strengths of echocardiography are evident from its heavy use and are not in great need of repetition.

Three dimensional echocardiography is also interesting and has great potential, but its current clinical role is not wide in comparison with two dimensional echocardiography, which is the clinical workhorse.

Morgan-Hughes et al raise the clinical role of coronary angiography using computed tomography. Although undoubtedly interesting, this is under evaluation, barely available in the United Kingdom, and studies indicating its value for guiding the decision to surgery are lacking. Controversy prevails over its potential future clinical role in relation to invasive coronary angiography.

Some would argue that to show established disease without showing the ischaemic burden is of little clinical value, particularly since intervention still requires an invasive approach. Aficionados who argue that computed tomography should be reserved for exclusion of coronary disease seem to treat radiation and contrast exposure as a commodity without burden. Unfortunately, widespread use in private reimbursement healthcare systems does not indicate suitability elsewhere. Prospective trials examining the balance of benefit, risk, and clinical utility are awaited with much interest.

Sanjay Prasad consultant cardiologist S.Prasad@rbh.nthames.nhs.uk

Ravi Assomull British Heart Foundation research fellow

Dudley J Pennell director

Cardiovascular Magnetic Resonance Unit, Royal Brompton and Harefield NHS Trust, London SW3 6NP

Competing interests: None declared.

\section{Four pillars of academic medicine need to be restored}

EdToR-Furness and Atkinson made several points that should be brought to the notice of the Department of Health, and the regional health departments of Scotland, Wales, and Northern Ireland, if clinical academic medicine of any quality is to be retained in the United Kingdom. ${ }^{12}$

All the talk about improving recruitment to academic medicine (in the United Kingdom) is pointless unless Abbasi's pillars of academic medicine-research, implementation of evidence, teaching, and improved delivery of health care-are restored for clinical academics. ${ }^{3}$ Under the current regime, university management has to deliver the requirements of the research assessment exercise. The only hope therefore lies in the BMA and the departments of health influencing the process of the research assessment exercise to allow points to be awarded in a manner that pays roughly equal respect to all of Abbasi's pillars-rather than just one-in relation to the work of clinical academics.

The loss of academic freedom referred to in Atkinson's letter requires further careful analysis and introspection by the powers that are implementing the research assessment exercise. Do we want to go down in history as the generation that screwed up academic freedom in the country that invented it?

Somnath Mukhopadhyay clinical senior lecturer (honorary consultant)

University of Dundee Medical School, Ninewells Hospital, Dundee DD1 9SY

s.mukhopadhyay@dundee.ac.uk

Competing interests: None declared.

1 Furness PN. Academic medicine: who is it for? BMJ 2005; 330:360. (12 February.)

Atkinson J. Academic medicine: who is it for? $B M J$ 2005;330:360. (12 February.)

3 Abbasi K. Editor's choice. The four pillars of global academic medicine. BMJ 2004;329. (2 October.)

\section{Alcohol in the body}

\section{Elimination of alcohol from blood varies}

EDITOR-Paton implies that elimination of alcohol from blood is always linear with time- - that is, zero order kinetics apply. ${ }^{1} \mathrm{He}$ also says that the process is mediated by enzymatic conversion. Enzyme activity, for most cases, can be assumed to follow first order reaction rates except when the rate limiting reaction is "saturated."

This point of saturation occurs for ethanol catabolism, in most non-Asian people, at somewhere between $55 \mathrm{mmol}$ and $65 \mathrm{mmol}$ of ethanol per litre of blood. Below these concentrations, alcohol elimination will proceed under conditions of first order kinetics. The characteristics for the individual at a given time may be determined by serial estimation of alcohol and subsequent calculation.
As said in the article, these characteristics may fluctuate between and within individuals depending on conditions at the time. The suggestion that alcohol is always eliminated by zero order kinetics is wholly misleading and can be dangerous if calculation of elimination of alcohol-for example, before administration of dimercaprol-is required.

Janusz Knepil principal biochemist (toxicology) Biochemistry Department, Gartnavel General Hospital, Glasgow G12 0YN jknepil@aol.com

Competing interests: None declared.

1 Paton A. Alcohol in the body. BMJ 2005;330:85-7. (8 January.)

\section{Author's reply}

EDITOR-My colleagues and I are well aware of the complexities of ethanol metabolism and elimination by the liver. But the $A B C$ of Alcohol is not a biochemical text; it is an introduction for clinicians-doctors, nurses, counsellors, therapists, social workerswho have to deal with the practical issues of alcohol misuse. ${ }^{1}$ Scientific rigour may therefore have to bow to a certain amount of simplification.

I prepared the fifth figure in the published extract from figures in an editorial by one of our group, Ken Lewis, a biochemist now retired, on the vexed question of back calculation of blood alcohol concentration, ${ }^{2}$ to illustrate one of the points that Knepil makes (figure).

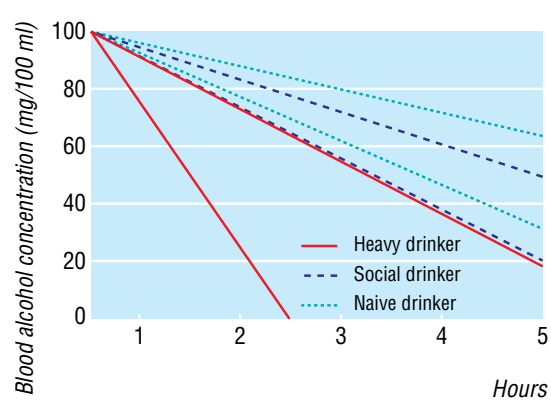

Rate of decrease of concentrations of alcohol in the blood in heavy, social, and naive drinkers. The two lines represent maximum and minimum rates for each category

Compare the rate of fall in blood alcohol concentration in naive and heavy drinkers. Why is the elimination of ethanol so much more rapid in heavy, and therefore habitual, drinkers than in someone who drinks only rarely? The probable answer is a combination of enzyme "induction"-that is, enhancement of enzyme activity by the alcohol itself-and recruitment of other enzyme groups to help deal with the added load of alcohol, hence the so called tolerance of experienced drinkers.

\section{Alex Paton retired consultant physician} Warborough, Oxfordshire OX10 7DJ PatonAlex@aol.com

Competing interests: None declared. 
1 Paton A, Touquet R, eds. $A B C$ of alcohol. 4th ed. Oxford: Blackwells and BMJ Books, 2005 .

blood alcohol concentration. BMJ 1987;295:800-1.

\section{Primary care research networks may herald new collaborations}

EDITOR-Chen and Majeed provide useful suggestions for how primary care research networks can work more closely with primary care trusts. ${ }^{1}$ This approach to joint working is likely to lead to more relevant research and better implementation of research findings.

"Pathways for Research" is an innovative development in which the South East London Strategic Health Authority and its six constituent primary care trusts work closely together with secondary care, higher education institutions, and primary care research networks. This initiative has been driven by the local NHS in recognition of the place of local and national research in underpinning and evaluating improvements in primary and community health care and the need to stimulate effective, relevant, and broadly based health services research. If successful this will provide a useful model of how such NHS led collaborations can work to the benefit of all.

Other opportunities exist to strengthen further the research infrastructure of general practice in the United Kingdom. For many years the concept of the "well-found laboratory" has formed the basis for infrastructure support for the basic medical sciences. ${ }^{2}$ It is time that the concept of the "well-found community laboratory" is taken seriously. It is a shame that the recent Medical Research Council e-science initiative was unable to fund primary care research in this area-the development of grid and thin client technology, together with new safeguards on patient data, offers exciting opportunities for large scale research in the community. It might also be appropriate that research of this kind is supported by other funding streams such as the Strategic Research Infrastructure Fund, which currently provides $£ 500 \mathrm{~m}(\$ 962 \mathrm{~m} ; € 720 \mathrm{~m})$ a year to higher education institutions.

Roger Jones professor of general practice and primary care

Department of General Practice and Primary Care, GKT School of Medicine, London SE11 6SP patricia.taylor@kcl.ac.uk

Adrian Eddleston chair, Pathways for Research South East London Strategic Health Authority, London SE1 7NT

Gill Rowlands director, STaRNet

Department of Community Health Sciences, St George's Hospital Medical School, London SW17 ORE

Competing interests: None declared.

1 Chen F, Majeed A. Primary care trusts and primary care research. BMJ 2005;330:56-7. (8 January)

2 May RM. Anniversary address 2003, Royal Society. http:// May RM. Anniversary address 2003 , Royal Society. http://
www.royalsoc.ac.uk/publication.asp?id = $2196 \quad$ (accessed 16 Mar 2005)

\section{Deficiencies in disaster funding}

Disasters less "telegenic" than the tsunami must not be forgotten

EDITOR-The tsunami disaster has been of increasing concern in the media, leading to one of the largest international charity movements, as described by Walker et al. But polemics began in France on 3 January 2005, when Pierre Salignon, director of Médecins sans Frontières (MSF), declared that his organisation had received enough donations for the victims of the tsunami, and that their plans for this operation were already fully financed.

He explained that MSF was still accepting money for other major humanitarian campaigns such as the slaughter in Darfur, Sudan, or AIDS in Africa, and he proposed that future donations received for South East Asia should be redirected elsewhere, after asking each contributor personally.

According to MSF, the funds collected in 15 days for this tragedy were six times those gathered for the earthquake in Bam in the same time or those collected for Darfur in two months. ${ }^{2}$ This very fact does raise a simple question: why did people give more and faster this time?

We think it is mainly because of the media coverage. The tsunami provided what economists call a "focal point." It happened just after Christmas, when people are usually less busy and the media do not have many interesting topics to report. Besides, Westerners on holiday were affected. Television networks showed so many sad stories about husbands having lost wives or children being the lone survivors of their families. Emotions were high and emotion guides altruistic help."

We must be careful that less "telegenic" causes are not forgotten.

Sébastien Tassy doctor

Service de Gériatrie, Hôpitale Sainte-Marguerite, 270 Boulevard Sainte Marguerite 13009, Marseilles, France

drsebastientassy@yahoo.fr

Guillaume Gorincour senior radiologist La Timone Children Hospital, F-13385, Marseilles, France

Competing interests: None declared.

1 Walker P, Wisner B, Leaning J, Minear L. Smoke and mirrors: deficiencies in disaster funding. BMJ 2005;330:247-50. (29 deficien

January)

Trecins sans Frontières Urgence en Asie. Pourquoi nous

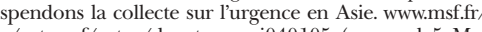
(accessed 5 Mar

3 Adolphs R. Cognitive neuroscience of human social behaviour. Nat Rev Neurosci 2003 Mar;4:165-78.

\section{Malaria epidemics are predicted in} tsunami regions from El Niño conditions

EDITOR-Walker et al describe the deficiencies in disaster funding. ${ }^{1}$ The association between the El Niño southern oscillation and health has been documented extensively, and it is now possible to predict these events with increasing accuracy. The National Oceanic and Atmospheric Administration concluded in late 2004 that E Niño conditions have developed and are expected to last through early $2005 .{ }^{2}$ Expected impacts included drier than average conditions over Indonesia and northern Australia until February 2005, ${ }^{2}$ followed by a period of raised temperatures.

An association between El Niño and malaria epidemics has been predicted for Papua New Guinea and West Papua, Indonesia. ${ }^{34}$ Historical records indicate that highland malaria epidemics in Papua follow periods of drought, evident during 1997-8 when a widespread epidemic affected many highland villages, some with extremely high death rates owing to lack of immunity and complete absence of treatment. $^{35}$ Highland epidemics often exhibited two peaks: one towards the end of the drought resulting from increased vector breeding, and one four to six months later, when increased temperatures shortened the sporogonic cycle.

Humanitarian attention is rightfully directed towards aiding victims of the tsunami in the region, but in the light of such a massive effort, possible events of seemingly lesser importance are often neglected. In view of the risk of focal epidemics in drought affected areas, it would be advantageous if healthcare professionals in the Papuan highlands were vigilant for possible malaria epidemics and had preventive or curative resources at their disposal.

Annemarie ter Veen research student

Annemarie.terVeen@lshtm.ac.uk

Menno Bouma honorary lecturer

London School of Hygiene and Tropical Medicine, Department of Infectious and Tropical Diseases, Disease Control and Vector Biology Unit, London WC1E 7HT

Michel van Herp epidemiologist

Medical Department, MSF-Belgium, rue Dupre 94, B1090 Brussels, Belgium

Kace Keiluhu assistant medical coordinator MSF-Belgium-Indonesia, Jln Kemang Utara No 32, Jakarta 12730, Indonesia

Budi Subianto head

Health Section, Unicef, PO Box 8318/JKSMP,

Jakarta 12083

\section{Competing interests: None declared.}

1 Walker P, Wisner B, Leaning J, Minear L. Smoke and mirrors: deficiencies in disaster funding. BMJ 2005;330:24750. (29 January.)

2 National Oceanic and Atmospheric Administration NOAA announces the return of El Niño. 10 September 2004. www.noaanews.noaa.gov/stories2004/s2317.htm 2004. www.noaanews.

3 Bangs M, Subianto B. El Niño and associated outbreaks of Beve M, Subianto B. El Nino and associated outbreaks of (a)

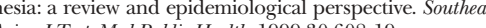

4 Schuurkamp GJ. Epidemiology of malaria and filariasis in the Ok Tedi region of western province, Papua New Guinea [PhD thesis]. University of Papua New Guinea,

5 Glantz MH, ed. Once burned, twice shy: lessons learned from the 1997-98 El Niño. Tokyo, Japan: UN University Press, 2001. 